\title{
STRUKTUR BIAYA PRODUKSI USAHATANI PAPRIKA DENGAN TEKNIK PENGAIRAN IRIGASI TETES
}

\section{PRODUCTION COST STRUCTURE OF PEPPER FARMING WITH DRIP IRRIGATION SYSTEM}

\author{
Reina Ayu Cecilia ${ }^{1}$, Sulistyodewi Nur Wiyono ${ }^{2 *}$, Zumi Saidah $^{2}$, Pandi Pardian $^{2}$ \\ ${ }^{1}$ Program Studi Agribisnis, Fakultas Pertanian, Universitas Padjadjaran \\ ${ }^{2}$ Departemen Sosial Ekonomi Pertanian, Fakultas Pertanian, Universitas Padjadjaran \\ Email: s.wiyono@unpad.ac.id
}

(Diterima 12-05-2021; Disetujui 24-06-2021)

\begin{abstract}
ABSTRAK
Paprika merupakan salah satu komoditas hortikultura yang memiliki peluang untuk dibudidayakan karena tingginya permintaan. Jumlah produksi paprika saat ini belum mampu memenuhi permintaan yang ada sehingga diperlukan upaya peningkatan produktivitas salah satunya dengan penerapan teknik pengairan drip irrigation system seperti yang dilakukan oleh CV. Cantigi. Penerapan teknik tersebut menyebabkan tingginya biaya sedangkan berbagai aspek dalam usahatani paprika selalu berubah dan dapat merubah tingkat keuntungannya. Analisis biaya produksi diperlukan untuk mengetahui biaya yang dikeluarkan dalam usahatani paprika. Tujuan penelitian ini adalah menjelaskan struktur biaya produksi usahatani paprika dengan teknik pengairan drip irrigation system. Metode analisis yang digunakan adalah metode kuantitatif deskriptif. Hasil analisis stuktur biaya menunjukkan rata-rata biaya produksi paprika sebesar Rp364.514.570,00 per tahun dengan rata-rata biaya tetap yang dikeluarkan sebesar Rp184.837.320,00 per tahun dan rata-rata biaya variabel sebesar Rp179.677.250,00 per tahun. Nilai kriteria investasi usahatani paprika dengan teknik pengairan drip irrigation system adalah Net $\mathrm{B} / \mathrm{C}$ sebesar 2,66, artinya usaha tersebut menguntungkan.
\end{abstract}

Kata Kunci: paprika, irigasi tetes, analisis biaya produksi

\section{ABSTRACT}

Paprika is one of the horticultural commodities that has the opportunity to be cultivated because of high demand. However, the amount of paprika production has not been able to fulfill the existing demand, so one of the efforts is to increase the productivity by applying the drip irrigation system. The application of these techniques leads to high costs while various aspects of paprika farming are always changing and can change the level of profits. Analysis of the structure of production costs is needed to determine the amount of costs incurred in paprika farming with the application of drip irrigation system. The purpose of this research is to explain the structure of production costs of paprika farming by applying the drip irrigation system. The analytical method used is descriptive quantitative method. The results shows the production costs incurred per year is Rp364.514.570,00 with an average fixed cost of Rp184.837.320,00 per year and the average variable cost of Rp179.677.250,00 per year. The value of investment shows a Net B / C of 2,66, which means it is profitable.

Keywords: paprika, drip irrigation system, cost analysis

\section{PENDAHULUAN}

Pertanian hortikultura di Indonesia memiliki banyak potensi yang bisa dikembangkan karena beragamnya

komoditas dan tingginya permintaan masyarakat akan produk hortikultura. 
Salah satu komoditas hortikultura yang memiliki potensi untuk dikembangkan dan nilai ekonominya tinggi adalah komoditas paprika (Cahyono, 2003). Permintaan paprika dari dalam negeri rata-rata sebanyak 15 ton per hari ditambah dengan permintaan pasar swalayan sebanyak $5 \mathrm{~kg}$ per hari (Prihmantoro, 2003). Permintaan tersebut tidak dapat terpenuhi secara optimal oleh para pelaku usahatani paprika dikarenakan jumlah produksinya yang masih terbatas (Prihmantoro, 2003). Pada tahun 2017 diketahui dari data BPS bahwa komoditas paprika memiliki angka jumlah produksi paling kecil dibandingkan dengan komoditas tanaman sayuran semusim lainnya. Jumlah produksi paprika pada tahun 2017 hanya mencapai 7.391 ton/tahun. Salah satu daerah penghasil paprika yang merupakan penghasil paprika terbesar di Indonesia adalah Provinsi Jawa Barat. Menurut data BPS pada tahun 2017, produksi paprika di Provinsi Jawa Barat mencapai 5.104 ton/tahun. Kabupaten Garut merupakan salah satu daerah penghasil paprika di Provinsi Jawa Barat yang memiliki keunikan dalam proses usahataninya dimana seluruh petani paprika yang ada di daerah tersebut telah menerapkan sistem irigasi tetes sebagai teknik pengairan dari usahatani paprikanya. Penerapan sistem irigasi tetes bisa menghasilkan penerimaan yang lebih tinggi dibandingkan dengan sistem pengairan konvensional karena produktivitas tanaman yang dihasilkan dari sistem tersebut juga lebih tinggi sehingga jumlah produksi yang dihasilkan lebih banyak (Andriyani, 2018). Salah satu perusahaan hortikultura di Kabupaten Garut yang sudah menerapkan sistem irigasi tetes sejak tahun 1998 adalah CV. Cantigi. Dalam kegiatan usahatani dengan penerapan sistem irigasi tetes ditemukan kendala dari segi biaya yaitu biaya investasi yang harus dikeluarkan jumlahnya cukup tinggi (Prihmantoro, 2003). Di sisi lain berbagai aspek dalam usahatani paprika selalu berubah dan dapat berdampak juga pada tingkat penerimaan dan keuntungan pelaku usahatani. Oleh karena itu, diperlukan analisis struktur biaya produksi dalam usahatani paprika dengan sistem irigasi tetes agar dapat diketahui jumlah dari biaya-biaya yang perlu dikeluarkan untuk usahatani paprika.

\section{METODE PENELITIAN}

Penelitian dilakukan di CV. Cantigi yang terletak di Desa Cikandang, Kecamatan Cikajang, Kabupaten Garut, 
Provinsi Jawa Barat. Waktu penelitian dilakukan adalah pada tanggal 1 November 2019 sampai dengan 7 November 2017.

Metode dalam penelitian ini ialah kuantitatif deskriptif. Kuantitatif deskriptif merupakan penelitian yang bertujuan untuk mendeskripsikan atau menjelaskan suatu peristiwa atau kejadian dalam bentuk hasil angka-angka yang bermakna (Sudjana, 2004).

Analisis data yang dilakukan dalam penelitian ini adalah analisis biaya produksi, analisis penerimaan, dan analisis keuntungan. Menurut Mulyadi (2005), analisis biaya produksi dilakukan dengan penjumlahan total biaya-biaya yang harus dikeluarkan selama proses usahatani dan terurai dalam rumus:

$$
\mathbf{T C}=\mathbf{T F C}+\mathbf{T V C}
$$

Keterangan:

$\mathrm{TC}=$ Total Biaya Produksi (Total Cost $)$

TFC $=$ Total Biaya Tetap (Total Fixed Cost $)$

$\mathrm{TVC}=$ Total Biaya Variabel (Total Variable Cost)

Menurut Hussain (2004), analisis penerimaan dapat dilakukan dengan rumus:

$$
\mathbf{T R}=\mathbf{P} \times \mathbf{Q}
$$

Keterangan:

$\mathrm{TR}=$ Total Penerimaan (Total Revenue)

$\mathrm{P} \quad=$ Harga Produk (Price)

$\mathrm{Q}=$ Jumlah Produk (Quantity)
Menurut Sukirno (2000), analisis keuntungan dapat dilakukan dengan menghitung marjin antara total biaya produksi dan penerimaan setelah dikenai pajak penghasilan. Rumus sederhana dari analisis keuntungan ialah:

\section{Keuntungan $=(T C-T R) \times$ Pajak}

Keterangan:

$\mathrm{TC}=$ Total Biaya Produksi (Total Cost $)$

$\mathrm{TR}=$ Total Penerimaan (Total Revenue)

Pajak yang digunakan adalah pajak penghasilan sebesar $25 \%$ berdasarkan ketetapan pemerintah dalam Pasal 17 Ayat 1 Bagian b UU No. 36 Tahun 2008 tentang Pajak Penghasilan.

Keuntungan juga dapat dihitung dari nilai Net Benefit/Cost atau Net B/C yang berupa perbandingan antara nilai sekarang yang diterima dan nilai sekarang yang dikeluarkan dan tercantum dalam rumus:

$$
\text { Net } \mathrm{B} / \mathrm{C}=\frac{\frac{\sum(\text { PV Positif })}{\sum(\text { PV Positif })}}{\sum(\text { PV Negatif })}
$$

Keterangan:

Net B/C = Rasio Keuntungan dan Biaya

PV Positif $=$ Nilai sekarang dari manfaat yang didapat

PV Negatif $=$ Nilai sekarang dari biaya yang dikeluarkan

Kriteria:

- Jika lebih besar (>) 1 maka usaha menguntungkan 
- Jika kurang dari (<) 1 maka usaha merugikan

\section{HASIL DAN PEMBAHASAN}

\section{Karakteristik Responden}

CV. Cantigi merupakan perusahaan pertanian yang khusus mengusahakan komoditas-komoditas hortikultura di Desa Cikandang, Kecamatan Cikajang, Kabupaten Garut. CV. Cantigi yang sebelumnya bernama Kelompok Tani Total Cantigi Farm telah berdiri sejak tahun 1998. Sejak awal berdiri, CV. Cantigi sudah memiliki spesialisasi dalam usahataninya dengan menanam berbagai komoditas sayuran eksklusif. Komoditas eksklusif pertama yang ditanam di CV. Cantigi adalah komoditas paprika. Sampai tahun 2019 luas lahan yang dimiliki perusahaan untuk kegiatan usahatani paprika adalah seluas $6.400 \mathrm{~m}^{2}$.

Aktivitas utama yang dilakukan dalam usahatani paprika di CV. Cantigi ialah terdiri atas pengadaan sarana produksi, proses produksi atau budidaya, dan pemasaran.

Sarana produksi yang dibutuhkan dalam usahatani paprika ialah lahan, tenaga kerja, modal, bangunan screen house, instalasi irigasi tetes, alat penunjang produksi, dan input produksi seperti media tanam, benih, nutrisi dan pestisida. Biaya yang dikeluarkan untuk memperoleh berbagai sarana produksi tersebut adalah seperti tercantum pada Tabel 1.

Tabel 1. Biaya Memperoleh Sarana Produksi

\begin{tabular}{clcr}
\hline No. & \multicolumn{1}{c}{$\begin{array}{c}\text { Sarana } \\
\text { Produksi }\end{array}$} & $\begin{array}{c}\text { Satuan } \\
\text { Waktu } \\
\text { (Tahun) }\end{array}$ & \multicolumn{1}{c}{$\begin{array}{c}\text { Biaya } \\
\text { (dalam }\end{array}$} \\
\hline 1. & Lahan & 1 & $38.400)$ \\
2. & Tenaga Kerja & 1 & 72.000 \\
3. & $\begin{array}{l}\text { Bangunan } \\
\text { Screen House }\end{array}$ & 5 & 245.632 \\
4. & $\begin{array}{l}\text { Instalasi Irigasi } \\
\text { Tetes }\end{array}$ & 5 & $104.295,4$ \\
5. & $\begin{array}{l}\text { Alat Penunjang } \\
\text { Produksi }\end{array}$ & 5 & $101.619,2$ \\
6. & Benih Paprika & 1 & $16.947,75$ \\
& Merah & & 20.682 \\
7. & Benih Paprika & 1 & 13.680 \\
& Kuning & & 102.810 \\
8. & Media Tanam & 1 & 1.800 \\
9. & Nutrisi & 1 &
\end{tabular}

Sumber : Data Primer CV. Cantigi

Proses produksi paprika kurang lebih memiliki tahapan pokok yang sama seperti proses produksi atau budidaya tanaman sayuran lain, yaitu meliputi beberapa kegiatan seperti penanaman, pemeliharaan, pemanenan, dan penanganan pasca panen. Sebelum melakukan penanaman, lahan di dalam screen house dipersiapkan terlebih dahulu dengan cara mensterilkan lingkungan screen house melalui penyemprotan formalin dan pestisida dalam batas penggunaan wajar. Kegiatan pensterilan dilakukan dengan tujuan 
membasmi hama dan penyakit yang mungkin ditinggalkan oleh tanaman paprika pada periode produksi sebelumnya. Penanaman paprika di dalam screen house dilakukan setelah benih paprika melalui masa penyemaian dan pembibitan selama kurang lebih 35 hari dan telah melewati proses aklimatisasi. Pada umur 35 hari setelah pembibitan tanaman siap untuk dipindahkan dari polybag semai ke polybag slab di dalam screen house. Dalam satu polybag slab terdapat 2 lubang tanam dan pada setiap 1 lubang tanamnya ditanami 2 bibit pohon paprika dengan varietas yang sama. Satu screen house dengan ukuran $800 \mathrm{~m}^{2}$ ditanami
$50 \%$ varietas paprika merah dan 50\% varietas paprika kuning. Terdapat 18 bedeng dalam satu screen house dimana 9 bedeng terdapat di sisi kiri dan 9 bedeng di sisi kanan. Dalam satu bedeng terdapat 38 lubang tanam, sehingga di satu screen house berukuran $8.000 \mathrm{~m}^{2}$ ditanami 684 tanaman. Keseluruhan populasi tanaman dalam screen house seluas $6.400 \mathrm{~m}^{2}$ adalah 10.944 tanaman. Dalam kegiatan penanaman, bahan dan barang yang diperlukan antara lain adalah polybag semai, polybag slab dan formalin. Rincian biaya yang dikeluarkan selama proses penanaman adalah seperti tercantum pada Tabel 2.

Tabel 2. Rincian Biaya Selama Proses Penanaman

\begin{tabular}{ccccccc}
\hline $\begin{array}{c}\text { Produksi } \\
\text { Tahun } \\
\text { Ke- }\end{array}$ & \multicolumn{2}{c}{ Polybag Semai } & \multicolumn{2}{c}{ Polybag Slab } & \multicolumn{2}{c}{ Formalin } \\
\cline { 2 - 6 } & $\begin{array}{c}\text { Kebutuhan } \\
(\mathrm{Kg})\end{array}$ & $\begin{array}{c}\text { Total Biaya } \\
(\mathrm{Rp} .1 .000)\end{array}$ & $\begin{array}{c}\text { Kebutuhan } \\
(\mathrm{Kg})\end{array}$ & $\begin{array}{c}\text { Total Biaya } \\
(\mathrm{Rp} .1 .000)\end{array}$ & $\begin{array}{c}\text { Kebutuhan } \\
(\mathrm{ml})\end{array}$ & $\begin{array}{c}\text { Total Biaya } \\
(\mathrm{Rp} .1 .000)\end{array}$ \\
\hline 1. & 44 & 1.100 & 438 & 10.950 & 500 & 175 \\
2. & 35 & 875 & 219 & 5.475 & 200 & 70 \\
3. & 44 & 1.100 & 438 & 10.950 & 500 & 175 \\
4. & 35 & 875 & 219 & 5.475 & 300 & 105 \\
5. & 44 & 1.100 & 438 & 10.950 & 500 & 175 \\
\hline
\end{tabular}

Sumber: Data Primer diolah, 2019

Pemeliharaan yang dilakukan dalam produksi atau budidaya paprika meliputi aplikasi nutrisi, aplikasi pestisida, penyulaman, pemasangan tali dan pelilitan, pewiwilan, seleksi cabang, seleksi buah, dan pengendalian hama dan penyakit.
Aplikasi nutrisi diberikan kepada tanaman melalui media air, nutrisi yang digunakan ialah satu set nutrisi AB Mix yang pada umumnya dijual di pasaran untuk budidaya tanaman-tanaman hidroponik. Campuran larutan nutrisi dan air yang digunakan adalah $1: 100$ terdiri atas 5L nutrisi $\mathrm{A}$, 5L nutrisi $\mathrm{B}$, dan 
1000L air. Pemberian nutrisi dilakukan dengan secara otomatis disalurkan lewat instalasi irigasi tetes dimana pada setiap 1 lubang tanam dalam polybag terdapat 1 regulating stick yang menyiramkan air dengan takaran yang ditentukan oleh operator atau pengelola screen house. Pada keadaan normal rata -rata pemberian nutrisi dilakukan sebanyak 5 kali dalam 1 hari. Pemberian nutrisi setiap harinya dimulai dari pukul $07.00-$ 17.00 dengan interval waktu jeda 2 jam. Biaya listrik untuk proses pengairan dengan sistem irigasi tetes untuk lahan screen house seluas $6.400 \mathrm{~m}^{2}$ adalah Rp3.000.000,00 per tahun dengan biaya per bulan Rp250.000,00.

Aplikasi pestisida dilakukan setiap 6 hari sekali setelah tanaman pindah tanam ke dalam screen house. Jenis pestisida yang digunakan ialah Previnecur, insektisida Decis bahan aktif Deltamektrin, dan fungisida Antracol yang masing masing dilarutkan ke dalam air dengan takaran $2 \mathrm{ml}$ zat per 1L air. Penggunaan insektisida dan fungisida disesuaikan dengan musim dan keadaan di dalam screen house. Pengaplikasian pestisida dilakukan dengan menggunakan power sprayer yang berbahan bakar solar. Dalam satu tahun perusahaan bisa menghabiskan sebanyak 50 liter solar dengan harga solar Rp5.150,00 maka total biaya yang dikeluarkan untuk bahan bakar solar adalah sebesar Rp275.500,00 per tahun. Penyulaman dilakukan dengan tujuan mempertahankan populasi tanaman. Tanaman mulai disulam pada usia 1-3 minggu setelah tanam. Penyulaman berlaku untuk tanaman yang terserang hama dan penyakit atau pun tanaman yang pertumbuhannya tidak normal sehingga dinilai kedepannya produksinya tidak akan maksimal. Tanaman disulam dengan varietas benih yang sama dan usia yang sama sehingga keseragaman produksi tetap tercapai.

Pemasangan tali dan pelilitan dilakukan dengan tujuan untuk mendirikan atau menegakan tanaman agar tidak rebah karena tanaman paprika bisa tumbuh tinggi sampai ketinggian maksimal 4 meter dan nantinya akan berbuah dengan bobot buah yang terbilang berat. Tali yang digunakan ialah tali tambang kecil yang biasa disebut turus, satu turus dipasang untuk 1 lubang tanam yang berisi 2 tanaman paprika. Fungsi dari turus ini sama dengan fungsi ajir pada umumnya, tali atau turus dipasang dari bagian atas screen house yaitu dengan dikaitkan ke kawat bentang yang terdapat di langit langit screen house dan bagian bawahnya dikaitkan ke 
sebilah bambu kecil di bawah polybag slab. Turus dipasang pada saat tanaman berusia 7-14 hari setelah tanam. Setelah turus dipasang, dilakukan pelilitan turus ke bagian batang tanaman searah jarum jam, batang tidak dililit terlalu kencang agar batang tidak rusak. Pelilitan dilakukan setiap 2 hari sekali untuk memastikan tali atau turus selalu menempel pada batang tanaman.

Pewiwilan adalah pembuangan cabang yang tidak dipelihara, bunga pertama yang muncul, bunga yang layu, bunga tua yang menempel pada buah, dan bunga yang rusak. Pewiwilan dilakukan 2 hari sekali sekaligus dengan kegiatan pelilitan. Pewiwilan dilakukan agar buah yang nantinya tumbuh bisa menghasilkan berat yang maksimal dan kualitas yang bagus.

Dalam satu tanaman hanya 2 cabang utama yang dipelihara, cabang yang dipilih adalah cabang yang paling kokoh dan memiliki sudut paling lebar dari batang tanaman. Pemilihan cabang dilakukan agar nutrisi terkonsentrasi pada buah yang akan dihasilkan dari cabang utama nantinya dan tidak terbagi dengan cabang lainnya yang mungkin kurang produktif. Seleksi buah dilakukan dengan cara penjarangan buah dalam setiap ruasnya, dalam satu ruas jumlah buah yang dipelihara tidak boleh lebih dari 5 buah. Selain itu juga dilakukan dengan membuang buah yang terserang hama dan penyakit secara parah, dan juga buah yang tumbuh secara abnormal.

Upaya pengendalian hama dan penyakit yang dilakukan oleh $\mathrm{CV}$. Cantigi ialah melalui 3 cara yaitu:

1. Secara preventif (pencegahan) dengan menjaga kebersihan dan melakukan sanitasi lingkungan secara rutin, memberikan pestisida, insektisida dan fungisida secara teratur dalam jumlah yang wajar.

2. Secara kuratif (pengobatan) dengan memberikan obat kepada tanaman yang terserang hama atau penyakit yang masih bisa diusahakan pemulihannya

3. Secara eradikatif (pemberantasan) dengan mencabut tanaman yang terserang hama atau penyakit jika keadaannya sudah di ambang batas normal agar tidak mempengaruhi pertumbuhan tanaman lain.

Kegiatan pemanenan paprika di CV. Cantigi bisa dilakukan dengan memenuhi beberapa standar operasional tertentu seperti umur dan kriteria panen, teknis pemanenan dan periode panen. Buah paprika matang sudah mulai bisa dipanen pada usia 75 hari setelah tanam. 
Tingkat kematangan buah yang akan dipanen tergantung permintaan pasar, bisa berupa buah belum matang yang berwarna hijau dan bisa berupa buah matang berwarna merah atau kuning. Buah paprika hijau dipanen pada usia 810 minggu, sedangkan buah paprika merah dan kuning bisa dipanen pada usia 10-12 minggu.

Kriteria panen buah paprika ialah buah yang ukurannya sudah cukup besar dengan ukuran diameter 7-12 $\mathrm{cm}$ dengan bentuk normal, warna muncul sempurna atau setidaknya $90 \%$ menunjukan kematangan, daging buah tebal, dan bebas dari hama penyakit.

Pemanenan buah paprika oleh CV. Cantigi dilakukan pada pagi hari. Bagian tangkai buah dipetik dengan menggunakan gunting stek secara perlahan. Rata-rata usia produktif tanaman paprika di CV. Cantigi mencapai 180 hari setelah tanam dengan usia panen sejak 75 hari setelah tanam. Masa panen buah paprika adalah 105 hari dengan interval kegiatan panen setiap 5 hari sekali. Dari satu tanaman paprika dalam 1 periode tanam bisa menghasilkan sebanyak 2,5-3 kg buah paprika.

Penanganan pasca panen yang dilakukan oleh CV. Cantigi ialah pengumpulan, sortasi dan grading, penyimpanan, pengemasan, dan pengangkutan.

Setelah buah selesai dipanen kemudian buah dikumpulkan dalam keranjang plastik berukuran lebar $60 \mathrm{~cm}$, panjang $35 \mathrm{~cm}$ dan tinggi $26 \mathrm{~cm}$. Selama proses pengumpulan, buah juga dibersihkan dari debu, kotoran dan residu pestisida atau obat yang menempel pada kulit buah. Sortasi juga dilakukan untuk memisahkan buah yang cacat atau rusak dengan buah yang kualitasnya baik. Grading dilakukan untuk menentukan tingkat kualitas buah untuk selanjutnya di pos-poskan sesuai permintaan berbagai segmen pasar. Adapun penentuan grading yang dilakukan oleh CV. Cantigi ialah berdasar kepada beberapa kriteria dalam Tabel 3.

Tabel 3. Kriteria Grading Buah Paprika di CV.Cantigi

\begin{tabular}{lccc}
\multicolumn{1}{c}{ Kriteria } & Grade A & Grade B & Grade C \\
\hline Ukuran/bobot buah & $250-350$ gr & $200-250$ gr & $<200$ gr \\
Bentuk & Normal, bagian bawah rata & Relatif normal & Kurang beraturan \\
Diameter & $8-12 \mathrm{~cm}$ & $7-10 \mathrm{~cm}$ & $3-5 \mathrm{~cm}$ \\
Tinggi & $7-10 \mathrm{~cm}$ & $6-10 \mathrm{~cm}$ & $2-4 \mathrm{~cm}$ \\
\hline
\end{tabular}

Sumber: Data Primer diolah, 2019

Setelah proses sortasi dan grading, hasil panen disimpan di tempat yang sejuk, CV. Cantigi tidak menyimpan buah paprika di dalam cool room karena 
suhu ruangan di Desa Cikandang sudah cukup untuk buah paprika tetap terjaga kesegarannya. Selain itu, juga karena CV. Cantigi tidak menyimpan buah paprika dalam jangka waktu yang panjang karena hasil panen rata-rata akan langsung dikemas dan dipasarkan. Hasil panen sebelum dipasarkan dilakukan pengemasan terlebih dahulu. CV. Cantigi mengemas buah paprika ke dalam 3 bentuk kemasan yaitu dikemas dalam plastik curah, kotak dus dan dengan cling wrap. Kemasan plastik curah digunakan untuk buah paprika yang dipasarkan ke pasar tradisional. Kapasitas dari satu kemasan plastik curah yang digunakan ialah mencapai $10 \mathrm{~kg}$. Kemasan plastik curah dibeli dalam satuan pack, satu pack plastik curah berisi 50 buah plastik.
Harga kemasan plastik curah per packnya ialah Rp35.000,00.

Kemasan untuk buah paprika yang dipasarkan ke pasar modern adalah kotak dus packing dan plasti cling wrap, namun kemasan cling wrap hanya diberlakukan jika ada permintaan khusus dari pihak pasar seperti dari supermarket. Kapasitas dari satu kemasan kotak dus packing mencapai 28 kg. Harga kemasan kotak dus packing per satuannya ialah Rp6.000,00. Harga plastic wrapping untuk kemasan cling wrap ialah Rp115.000,00 per satu gulung dengan panjang 500m. Rincian kebutuhan dan total biaya yang dikeluarkan untuk kegiatan pengemasan tercantum pada Tabel 4.

Tabel 4. Kebutuhan dan Total Biaya Dalam Kegiatan Pengemasan

\begin{tabular}{ccccccc}
\hline $\begin{array}{c}\text { Produksi } \\
\text { Tahun } \\
\text { Ke- }\end{array}$ & \multicolumn{2}{c}{ Plastik Curah } & \multicolumn{2}{c}{ Dus Packing } & \multicolumn{2}{c}{ Plastik Wrapping } \\
\cline { 2 - 7 } & $\begin{array}{c}\text { Kebutuhan } \\
\text { (Kg) }\end{array}$ & $\begin{array}{c}\text { Total Biaya } \\
(\text { Rp.1.000) }\end{array}$ & $\begin{array}{c}\text { Kebutuhan } \\
(\text { Pcs })\end{array}$ & $\begin{array}{c}\text { Total Biaya } \\
(\text { Rp.1.000) }\end{array}$ & $\begin{array}{c}\text { Kebutuhan } \\
\text { (Gulung) }\end{array}$ & $\begin{array}{c}\text { Total Biaya } \\
\text { (Rp. 1.000) }\end{array}$ \\
\hline 1. & 32 & 1.120 & 400 & 2.400 & 5 & 575 \\
2. & 34 & 1.190 & 300 & 1.800 & 6 & 690 \\
3. & 35 & 1.225 & 400 & 2.400 & 6 & 690 \\
4. & 30 & 1.050 & 300 & 1.800 & 4 & 460 \\
5. & 29 & 1.015 & 400 & 2.400 & 4 & 460 \\
\hline
\end{tabular}

Sumber: Data Primer diolah, 2019

Pengangkutan hasil panen untuk dipasarkan ke pasar tradisional yang ada di sekitar Kota Garut dan Kota Bandung dilakukan dengan menggunakan mobil minibus atau mobil pick up. Begitu juga untuk hasil panen yang dipasarkan ke pasar modern seperti supermarket, hotel dan restauran. Terlebih karena penjualan ke pasar modern dilakukan melalui mitra kerjasama yang berada di daerah Kota/Kabupaten Garut dan Kota/Kabupaten Bandung sehingga pengangkutan seringkali dilakukan secara bersamaan. Biaya bahan bakar bensin 
yang dianggarkan per tahunnya ialah sebesar Rp5.355.000,00. Hasil panen yang dipasarkan keluar Kota Bandung seperti ke Yogyakarta, Malang dan Bali dikirim melalui angkutan umum dengan biaya pengiriman sebesar Rp100.000,00 per satu kali pengiriman. Biaya pengiriman yang dianggarkan ialah sebesar Rp1.500.00,00 per tahunnya.

Kegiatan pemasaran paprika oleh CV. Cantigi dilakukan melalui 3 saluran pemasaran. Pada saluran pertama terdiri atas produsen dan konsumen. Saluran kedua terdiri atas produsen, bandar, toko ritel dan konsumen. Pada saluran pemasaran ketiga pelaku yang terlibat adalah produsen, mitra, supermarket dan industri pengolahan, serta konsumen.

Pada saluran pertama, pemasaran yang dilakukan ialah menjual produk langsung kepada konsumen. Biasanya konsumen datang langsung ke tempat produksi untuk mengambil barang yang sudah dipesan sebelumnya. Selain konsumen yang datang ke tempat produksi, CV. Cantigi sebagai produsen juga sering kali mengantarkan barang pesanan langsung kepada konsumen. Konsumen yang dituju dalam saluran pemasaran ini ialah seperti pengusaha catering, hotel dan home industry lainnya yang ada di sekitar Kota dan Kabupaten Garut.

Saluran pemasaran yang kedua memiliki alur yang bermula dari produsen, bandar, sampai ke toko ritel dan pada akhirnya bermuara kepada konsumen akhir. CV. Cantigi sebagai produsen biasanya menjual hasil panen ke pasar induk yang ada di Kota Bandung dan pasar daerah yang ada di sekitar Kabupaten Garut, Kota Garut. Pada saat penjualan ke pasar pasar tersebut, $\mathrm{CV}$. Cantigi menjual hasil panen ke bandar yang ada di pasar, baru kemudian dari bandar disebarkan atau dijual ke toko ritel di pasar tersebut dan toko ritel menjual produk ke konsumen akhir.

Pada saluran pemasaran ketiga, hasil panendari CV. Cantigi dijual ke pasar modern melalui beberapa mitra kerjasama seperti PT. Alamanda, Amazing Farm, dan S3 yang semula bernama PT. Saung Mirwan. CV. Cantigi mengantarkan hasil panen ke mitra tersebut menggunakan mobil pick up atau mobil operasional perusahaan dikarenakan lokasi mitra yang masih berada di sekitar Kota Garut dan juga Kota Bandung. Penjualan hasil panen untuk pasar modern dilakukan melalui mitra-mitra tersebut karena yang bersangkutanlah yang sudah memilliki 
izin dan perjanjian jual beli dengan pihak supermarket dan industri pengolahan besar lainnya.

Biaya investasi dari usahatani paprika terdiri atas biaya bangunan screen house, instalasi irigasi tetes, dan alat-alat penunjang produksi. Biaya pembangunan screen house ialah sebesar Rp245.632.000,00. Biaya pembuatan instalasi irigasi tetes sebesar Rp104.295.400,00. Biaya pembelian alatalat penunjang produksi ialah sebesar Tabel 5. Rincian Biaya Tetap (Rp. 1.000)

\begin{tabular}{ccccc}
\hline Tahun & Sewa Lahan & Gaji dan THR & Penyusutan & Total \\
\hline 1. & 38.400 & 72.000 & $70.437,32$ & $184.837,32$ \\
2. & 38.400 & 72.000 & $70.437,32$ & $184.837,32$ \\
3. & 38.400 & 72.000 & $70.437,32$ & $184.837,32$ \\
4. & 38.400 & 72.000 & $70.437,32$ & $184.837,32$ \\
5. & 38.400 & 72.000 & $70.437,32$ & $184.837,32$ \\
\hline
\end{tabular}

Sumber : Data Primer diolah, 2019

Biaya tetap yang dikeluarkan dalam usahatani paprika adalah sebesar Rp184.837.320,00. Biaya variabel dalam usahatani paprika dengan sistem irigasi tetes adalah terdiri atas biaya pembelian benih paprika, media tanam, polybag, nutrisi, pestisida, formalin, bensin, listrik dan kemasan produk. Rincian rata-rata biaya variabel dalam usahatani paprika dapat dilihat dalam Tabel 6 .

Tabel 6. Rincian Rata-rata Biaya Variabel

\begin{tabular}{llr}
\multicolumn{1}{c}{ (Rp. 1.000) } \\
\hline No. & Jenis Biaya & $\begin{array}{c}\text { Rata-rata Biaya } \\
\text { Variabel }\end{array}$ \\
\hline 1. & Benih Paprika & $16.947,75$ \\
& Merah & 20.682.
\end{tabular}

Rp101.619.200,00. Total biaya usahatani paprika adalah sebesar Rp70.437.320,00.

Biaya produksi paprika terdiri atas biaya tetap dan biaya variabel. Biaya tetap paprika terdiri atas biaya sewa lahan, gaji tenaga kerja, THR dan bonus, serta biaya penyusutan. Rincian biaya tetap dalam usahatani paprika adalah seperti terlihat dalam Tabel 5. penyusutan dari investasi dalam 
Rp179.677.250,00. Total biaya produksi paprika dengan sistem irigasi tetes ialah sebesar Rp364.514.570,00. Produktivitas tanaman paprika dari hasil usahatani dengan sistem irigasi tetes bisa mencapai $3 \mathrm{Kg}$ per tanaman. Populasi tanaman paprika untuk lahan screen house seluas $6.400 \mathrm{~m}^{2}$ adalah sebanyak 10.944 tanaman. Jika dalam kondisi normal maka jumlah produksi tanaman paprika per tahun adalah sebanyak $32.832 \mathrm{Kg}$. Berdasarkan hasil wawancara dengan manajer teknik dan budidaya $\mathrm{CV}$. Cantigi, persentase jumlah produksi paprika hijau, merah dan kuning adalah masing-masing sebesar 40\%, 30\% dan $30 \%$ dari total jumlah produksi per tahun. Artinya jumlah produksi paprika hijau ialah sebanyak 13.132,8 kg, paprika merah dan kuning masing-masing sebanyak 9.849,6 kg. Menurut keterangan manajer teknik dan budidaya $\mathrm{CV}$. Cantigi, jumlah produksi paprika berfluktuasi setiap tahunnya seperti terjadi kenaikan pada tahun kedua dan ketiga usaha dan penurunan pada tahun keempat dan kelima. Hasil produksi paprika di CV. Cantigi dibagi menjadi beberapa kategori kelas atau grade sesuai dengan kualitas buah. Grade atau kelas kualitas buah yang ditetapkan oleh CV. Cantigi terdiri atas 4 grade yaitu grade
A, B, C dan Cx. Menurut manajer teknik dan budidaya tanaman CV. Cantigi, ratarata persentase hasil produksi paprika setiap grade nya adalah masing masing sebesar $0 \%$ untuk paprika grade A, 40\% grade $\mathrm{B}, 20 \%$ grade $\mathrm{C}$, dan $10 \%$ grade Cx. Kisaran harga jual paprika hijau dari grade A sampai grade $\mathrm{Cx}$ adalah Rp10.000 - Rp25.000. Harga jual paprika merah adalah Rp15.000 - Rp30.000. Harga jual paprika kuning adalah Rp17.000 - Rp37.000. Dalam keadaan produktivitas normal atau sebanyak $3 \mathrm{Kg}$ per tanaman dan dengan harga jual tersebut maka penerimaan yang didapat oleh CV. Cantigi adalah sebesar Rp809.308.800,00 per tahun. Adapun penerimaan yang diperoleh dari hasil penjualan dapat dilihat pada Tabel 7 .

Tabel 7. Penerimaan Usahatani Paprika di CV. Cantigi

\begin{tabular}{cc}
\hline Jenis Paprika & $\begin{array}{c}\text { Penerimaan (dalam } \\
\text { Rp1.000) }\end{array}$ \\
\hline Paprika Hijau & $258.716,16$ \\
Paprika Merah & $243.285,12$ \\
Paprika Kuning & $307.307,52$ \\
\hline Total Penerimaan & $809.308,8$ \\
\hline Sumber: Data Primer
\end{tabular}
Sumber: Data Primer diolah, 2019

Keuntungan yang didapat oleh perusahaan adalah hasil dari selisih total biaya produksi dan penerimaan setelah dikenai pajak penghasilan sebesar $25 \%$. Keuntungan yang didapatkan CV. Cantigi dari kegiatan usahataninya adalah ratarata sebesar Rp333.595.672,5 per tahun. 
Kegiatan usahatani paprika yang dengan sistem irigasi tetes dilakukan oleh CV. Cantigi menguntungkan.

menggunakan modal awal yang berasal dari bank pemerintah dengan suku bunga dasar kredit sebesar 12,21\%. Perhitungan Net $\mathrm{B} / \mathrm{C}$ dilakukan dengan membandingkan nilai penerimaan setelah dikenai suku bunga dasar kredit dengan total biaya yang telah dikeluarkan. Nilai Net $\mathrm{B} / \mathrm{C}$ dari usahatani paprika dengan sistem irigasi tetes yang dilakukan oleh CV. Cantigi adalah sebesar 2,66. Artinya setiap tambahan biaya sebesar Rp1,00 akan menghasilkan nilai manfaat sebesar Rp2,66 bagi perusahaan. Dapat disimpulkan bahwa usahatani paprika dengan sistem irigasi tetes menguntungkan.

\section{KESIMPULAN DAN SARAN}

\section{Simpulan}

Biaya produksi yang dikeluarkan dalam usahatani paprika dengan teknik pengairan drip irrigation system ialah rata-rata sebesar Rp364.514.570,00 per tahun dengan rata-rata biaya tetap sebesar Rp184.837.320,00 per tahun dan rata-rata biaya variabel sebesar Rp179.677.250,00 per tahun. Nilai Net B/C usahatani paprika dengan sistem irigasi tetes adalah sebesar 2,66. Artinya usahatani paprika

\section{Saran}

Mengoptimalkan penggunaan faktor-faktor produksi sehingga jumlah hasil produksi dapat lebih meningkat. Seperti halnya memanfaatkan semaksimal mungkin instalasi drip irrigation system yang bisa digunakan untuk lahan seluas maksimal $3.200 \mathrm{~m}^{2}$. Dengan pemaksimalan manfaat faktor produksi tersebut maka kemungkinan hasil produksi yang lebih tinggi bisa diperoleh karena populasi tanaman yang ditanam lebih banyak sedangkan biaya investasi tertentu jumlahnya tidak meningkat.

Membuat jadwal pola tanam dengan menyesuaikan jadwal panen dengan waktu-waktu permintaan datang agar pada saat permintaan dan harga jual tinggi, perusahaan dapat meraih keuntungan yang optimal.

Selain itu juga melakukan kontrol lapangan terhadap tenaga kerja penanggung jawab screen house agar kegiatan pemeliharaan dapat terawasi dengan baik dan meminimalisir kesalahan dalam pemeliharaan yang bisa mengakibatkan penurunan jumlah produksi. 


\section{DAFTAR PUSTAKA}

Andriyani, C. N. (2018). Analisis Biaya Budidaya Paprika Hidroponik Dengan Sistem Irigasi Tetes Kelompok Tani GG Lembang . Jurnal Karya Ilmiah Mahasiswa Agribisnis .

[BPS] Badan Pusat Statistik. 2018. Produksi Hortikultura Sayuran dan Buah Buahan Semusim Tahun 2017 di Jawa Barat. Bandung.

. Badan Pusat Statistik. 2018. Statistik Tanaman Sayuran dan Buah Semusim Indonesia. Jakarta.

Cahyono, B. (2003). Cabai Paprika, Teknik Budidaya dan Analisis Usahatani. Yogyakarta: Kanisius.
Hussain. (2004). Manajemen Bisnis Terhadap Penerimaan Produksi. Jakarta : PT. Gramedia Pustaka Utama.

Mulyadi. (2005). Penggolongan Biaya. Jakarta: Kencana.

Prihmantoro, H. I. (2003). Paprika Hidroponik dan Non Hidroponik. Jakarta: Penebar Swadaya.

Sudjana, N. (2004). Statistika Deskriptif. Bandung: Sinar Baru Algensindo Offset.

Sukirno, S. (2000). Makro Ekonomi Modern. Jakarta: PT. Raja Grafindo Perkasa. 